\title{
O direito do idoso frente aos reajustes de planos de saúde
}

\section{Elderly People's rights pertaining to health insurance readjustment}

\author{
Dimas Tafelli ${ }^{1}$, Enio Trujillo ${ }^{1}$, Fábio Duarte da Costa Aznar ${ }^{2}$, Adriana \\ Rodrigues de Freitas ${ }^{2}$, Sílvia Helena de Carvalho Sales Peres ${ }^{3}$, José Roberto de \\ Magalhães Bastos ${ }^{3}$, Arsenio Sales-Peres ${ }^{3}$, Magali de Lourdes Caldana ${ }^{3}$
}

\begin{abstract}
Tafelli D, Trujillo E, Aznar FDC, Freitas AR, Peres SHCS, Bastos JRM, Sales-Peres A, Caldana ML. O direito do idoso frente aos reajustes de planos de saúde. Saúde, Ética \& Justiça. 2015;20(2):93-101.

RESUMO: O envelhecimento populacional cada vez mais tem chamado a atenção das autoridades, sendo necessário que a legislação vigente crie subsídios que visem permitir condições de vida mais justas e adequadas aos idosos. Atenta a tal realidade, a Constituição Federal preocupou-se em tutelar a saúde do idoso, prevendo a efetiva proteção jurídica de tais indivíduos. No entanto, a evolução do direito à saúde é gradativa e lenta, sendo que somente recentemente se deu a promulgação do "Estatuto do Idoso", que discorre sobre a efetiva garantia da impossibilidade de reajustes nas mensalidades dos planos de saúde de idosos em percentual além do permissivo legal, tanto pelo avanço da idade, quanto pelo aumento da sinistralidade. Destaca-se também a aplicabilidade do Código de Defesa do Consumidor, norma protetiva e aplicável na relação contratual, que também possui regulamentação legal específica e que dialoga com as demais normas protetivas aos direitos dos idosos. Assim, a análise ora pretendida objetiva promover uma visão crítica e analítica sobre as disposições legais e o entendimento jurisprudencial dominante a respeito da impossibilidade de majoração das mensalidades dos planos de saúde de idosos além do permissivo legal. Para tanto, parte-se do estudo da evolução das normas que tratam do assunto, bem como do material existente na literatura nacional, além da pesquisa dos sites nos Tribunais de Justiça do Brasil para extração de decisões atuais relacionadas ao tema. Observou-se a ocorrência de abusos das operadoras dos planos de saúde que, mesmo existindo expressa proibição legal, corriqueiramente majoram indevidamente as mensalidades dos planos de saúde de idosos.
\end{abstract}

DESCRITORES: Saúde do idoso; Direitos dos idosos; Defesa do consumidor; Planos de pré-pagamento em saúde.

\footnotetext{
1. Mestrando em Odontologia em Saúde Coletiva, Faculdade de Odontologia de Bauru, Universidade de São Paulo.

2. Doutor em Odontologia em Saúde Coletiva, Faculdade de Odontologia de Bauru, Universidade de São Paulo.

3. Professor Doutor, Faculdade de Odontologia de Bauru, Universidade de São Paulo.

Endereço para correspondência: Dimas Tafelli. Departamento de Odontologia em Saúde Coletiva - Faculdade de Odontologia de Bauru. Alameda Dr. Otávio Pinheiro Brisola, 9-75. Bauru - SP. CEP: 17012-901. E-mail: dimas.tafelli@usp.br
} 


\section{INTRODUÇ̃̃̃O}

$\mathbf{O}$ envelhecimento populacional, com todas as suas peculiaridades sociais, políticas, econômicas, biológicas e psicológicas, é um desafio, principalmente para os países em desenvolvimento ${ }^{1}$. Sendo assim, é necessário que a legislação vigente crie subsídios que visem permitir condições de vida mais justas e adequadas à população idosa.

A proteção do idoso no ordenamento jurídico vigente está alicerçada constitucionalmente, pela previsão no caput do art. 230 da Constituição Federal ${ }^{2}$. Referida disposição indica que "A família, a sociedade e o Estado têm o dever de amparar as pessoas idosas, assegurando sua participação na comunidade, defendendo sua dignidade e bem-estar e garantindo-lhes o direito à vida".

Em um segundo aspecto, porém não em menor relevância jurídica, além do texto constitucional, o Estatuto do Idoso, Lei n. ${ }^{\circ} 10.741 / 2003^{3}$, dispõe expressamente sobre uma série de medidas protetivas, sendo que no campo específico de proteção à saúde existe a disposição clara do $\S 3^{\circ}$, do art. 15 , quanto à vedação de discriminação do idoso nos planos de saúde pela cobrança de valores diferenciados em razão da idade, para que não haja discriminação dos idosos relativamente aos demais usuários de plano de saúde.

É certo que a intenção da legislação foi justamente evitar a inviabilidade do acesso do idoso aos meios de proteção à sua saúde, tendo em vista situações recorrentes no que diz respeito ao aumento abusivo nas mensalidades de planos de saúde na faixa etária, sobretudo a partir dos 60 (sessenta) anos.

Como se não bastasse, tem-se também a aplicabilidade nestes casos do Código de Defesa do Consumidor (C.D.C. $)^{4}$, norma importante, protetiva e que reconhece que qualquer desequilíbrio e abusividade contratual serão considerados nulos, em especial se houver estabelecimento de obrigações consideradas iníquas, abusivas ou que coloquem o consumidor em desvantagem exagerada, ou seja, incompatíveis com os princípios da boa-fé ou da equidade.

Atendendo ao espírito legislativo, em especial às disposições da Lei n. ${ }^{\circ} 9.656 / 1998^{5}$, que regulamenta a atuação das operadoras de plano de saúde no Brasil, foi criada a Agência Nacional de Saúde Suplementar (A.N.S.), que desempenha papel fundamental na normatização de ações relacionadas aos prestadores de serviços de saúde suplementar, acompanhando as relações entre prestadores e operadoras, inclusive em relação aos contratos firmados, discutindo e propondo critérios de qualidade para monitoramento da atuação de prestadores no mercado, ditando resoluções que detalham a intrincada relação entre profissionais, usuários e estabelecimentos. Neste contexto, exsurge a Resolução
Normativa da A.N.S. n. ${ }^{\circ} 63$, de 22 de dezembro de $2003^{6}$, que definiu os limites para adoção de variação de preço por faixa etária nos planos privados de assistência à saúde, objeto do presente estudo.

\section{OBJETIVO}

O presente estudo teve como objetivo discutir a abusividade referente à majoração excessiva de preços e reajustes acima do permissivo legal perpetrados pelas operadoras em planos de saúde de usuários idosos.

\section{MÉTODOS}

Foi analisado o material existente na legislação nacional, no que diz respeito à proteção dos direitos dos idosos na relação com as operadoras de planos de saúde, considerando a Constituição Federal, a legislação infraconstitucional, e a consulta de decisões relativas ao tema de Tribunais de Justiça pátrios. Foram consultados os bancos de dados dos sites do Tribunal de Justiça do Estado de São Paulo, do Superior Tribunal de Justiça e do Supremo Tribunal Federal, utilizando-se os descritores para pesquisa "planos de saúde", "reajustes", "defesa do consumidor" e "direitos dos idosos". Os parâmetros de tempo cingiram-se ao período de 10 anos, com termo inicial contado da data do julgamento.

\section{DESENVOLVIMENTO}

A Constituição Federal ${ }^{2}$ consagra como fundamentos do Estado a soberania, a cidadania, a dignidade da pessoa humana, os valores sociais do trabalho e da livre iniciativa e do pluralismo político. São, na verdade, valores estruturantes que delineiam o alicerce da República Federativa do Brasil. Estes preceitos estão expostos nos incisos do artigo $1^{\circ}$, e possuem especial significado dentro da ordem constitucional, por expressarem premissas básicas que, muito embora não dispostas em um plano hierárquico, possuem elevado grau axiológico.

Nesse mesmo sentido e corroborando a premissa básica do artigo supramencionado, os incisos I ao LXXVII do art. $5^{\circ}$ elencam os direitos e garantias fundamentais que, em planos distintos, contemplam direitos relacionados à liberdade e à igualdade, com o escopo claro de promover a dignidade da pessoa humana ${ }^{2}$.

A dignidade da pessoa humana, um dos fundamentos do Estado, constitui-se, portanto no valor constitucional supremo em torno do qual gravitam todos os demais direitos fundamentais, o que implica na afirmação de que o restante do ordenamento jurídico deve levar em consideração, em primeiro lugar, o respeito a tal princípio. Trata-se do fundamento, da origem e do ponto 
de coincidência entre os direitos fundamentais.

Já em relação ao tratamento da saúde, a estrita observação desta premissa torna-se ainda mais evidente e necessária. A Constituição Federal ${ }^{2}$ posiciona o direito à saúde como um direito social, lecionando no seu art. $6^{\circ}$ que:

São direitos sociais a educação, a saúde, a alimentação, o trabalho, a moradia, o transporte, o lazer, a segurança, a previdência social, a proteção à maternidade e à infância, a assistência aos desamparados, na forma desta Constituição.

Desta disciplina advém a exigência dos poderes públicos de prestações positivas com vistas a assegurar a previsão constitucional, exigindo-se políticas públicas que concretizem as prerrogativas individuais e coletivas, destinadas à redução das desigualdades existentes e a garantir uma existência humana digna.

Não é por outra razão que a própria Constituição Federal $^{2}$ prevê em seu art. 196 que "A saúde é direito de todos e dever do Estado, garantido mediante políticas sociais e econômicas que visem à redução do risco de doença e de outros agravos e ao acesso universal e igualitário às ações e serviços para sua promoção, proteção e recuperação."

O direito à saúde é, portanto, direito oponível ao Estado, aparecendo em vários artigos da Constituição Federal $^{2}$, com destaque especial nos arts. 196, 197 e 198. Há a imposição ao Estado do dever de garantia à saúde da população, assegurando ao cidadão o acesso universal e igualitário às ações e serviços, que visam a promoção, proteção e recuperação da saúde dos indivíduos.

O Estado reconhece, portanto, que a saúde é direito de todos os cidadãos, indiscriminadamente, bem como dever de si próprio. No entanto, por meio do art. 197 abre também a possibilidade de sua execução ser feita diretamente pelo Poder Público ou, sob sua fiscalização e controle, pela iniciativa privada ${ }^{2}$. O que se tem em vista então é que a assistência à saúde é livre à iniciativa privada, que de fato participa atualmente de forma complementar ao Sistema Único de Saúde, segundo as diretrizes fixadas pelo Poder Público.

Analisando-se a questão sob a ótica constitucional quanto às atividades a que o Estado brasileiro está sujeito, é possível afirmar a existência de grandes desafios e dificuldades que até a presente data não permitiram a constatação da consolidação completa da assistência estatal, com acesso amplo, equitativo e universal à saúde para todos os cidadãos, de modo que existem ainda grandes desequilíbrios, contradições e carências dentro do sistema público de saúde ${ }^{7}$, previsto na Constituição Federal $^{2}$.

Após longos anos de vigência da Constituição Federal e intensas discussões e estudos, foi editada norma que trata da regulamentação, fiscalização e controle dos serviços de saúde (Lei n. ${ }^{0}$ 9.656/1998) ${ }^{5}$, que dispõe especificamente sobre planos e seguros privados de assistência à saúde. Referida norma pode ser considerada um marco na questão da saúde no Brasil, já que, enfim, conferiu-se aplicabilidade plena aos dispositivos constitucionais mencionados acima que possuem eficácia limitada e dependiam de regulamentação legislativa para efetivamente gerarem seus efeitos.

Com a edição da referida lei chegou-se à conclusão inequívoca e praticamente pacificada de que, se a Lei Maior faculta à iniciativa privada participar da assistência à saúde de forma complementar, sendo certo também afirmar que se tais prestadores de serviços servem para suprir de alguma forma deficiências estatais mediante autorização constitucional, à semelhança do que ocorre com o próprio Estado, devem garantir o direito à saúde, não havendo que se cogitar em limitações de quaisquer ordens na obtenção e proteção deste bem maior, resguardados obviamente os limites e premissas contratuais, na busca do equilíbrio atuarial da relação obrigacional existente entre o consumidor e a operadora de plano de saúde.

Pacífico também é o entendimento de que o contrato de plano de saúde submete-se aos ditames do C.D.C. ${ }^{4}$, ainda que a avença tenha sido celebrada antes da vigência desse diploma, já que há a possibilidade de se aferir, nas renovações contratuais, a abusividade de cláusulas à luz do que dispõe a legislação consumerista ${ }^{8}$. A aplicabilidade do codex consumerista também advém do teor da Súmula $469^{9}$ do Superior Tribunal de Justiça, que indica de forma expressa "aplica-se o C.D.C. aos contratos de plano de saúde", cuja aspiração é também seguida pela Súmula 100 do Tribunal de Justiça do Estado de São Paulo ${ }^{10}$.

Atendendo às premissas da Lei n. ${ }^{\circ}$ 9.656/1998 foi criada por meio da Lei n. ${ }^{\circ} 9.961 / 2000^{11}$ a A.N.S., visto que até então este setor da economia não possuía padrão de funcionamento. O referido órgão governamental é vinculado ao Ministério da Saúde, com o escopo claro de regular a atuação das operadoras setoriais, promovendo a defesa do interesse público na assistência suplementar à saúde, fomentando uma série de medidas e ações governamentais, com a criação de normas, controle e fiscalização do segmento dos Planos de Saúde. Deste modo, toda e qualquer modalidade de produto, serviço ou contrato ligado aos planos e seguros privados de assistência à saúde ficaram subordinados às normas e à fiscalização da referida agência.

No que diz respeito à saúde dos idosos, indivíduos com mais de 60 (sessenta) anos de idade, é correto afirmar que o envelhecimento é um fenômeno universal e inexorável, característico dos países centrais e também dos países em desenvolvimento, caso do Brasil. Dentre outros fatores, o crescimento da população de idosos 
está diretamente ligado ao aumento da longevidade da população e também à redução dos níveis de fecundidade ${ }^{12}$.

Reconhecendo o crescimento de tal população no Brasil de forma sistemática e relevante, a Constituição Federal do Brasil $^{2}$ e a legislação infraconstitucional acolheram a proteção de tais indivíduos. As estatísticas continuaram a confirmar tais premissas, sendo que o Instituto Brasileiro de Geografia e Estatística (IBGE) em Censo Demográfico realizado em 2010 apontou a existência de aproximadamente 21 milhões de pessoas com 60 anos ou mais ${ }^{13}$, evidenciando-se que o ritmo de crescimento da população idosa tem sido sistemático e consistente, o que gera necessidade de mudanças na estrutura social, para que essa população alcance de fato o seu espaço, com atividades físicas, independência e consequentemente obtenção de melhor qualidade de vida.

Reconhecendo então tais questões, foi editada a Lei n. ${ }^{\circ} 10.741 / 2003^{3}$, o chamado Estatuto do Idoso. Referida norma traz à baila diversos programas normativos, notadamente aqueles relacionados à saúde, os quais estabelecem enfim competência para sua efetivação. Em relação ao direito à saúde do idoso, referida lei dedica a integralidade do Capítulo IV, trazendo no art. 15 a previsão específica a respeito de tal questão:

É assegurada a atenção integral à saúde do idoso, por intermédio do Sistema Único de Saúde - SUS, garantindo-lhe o acesso universal e igualitário, em conjunto articulado e contínuo das ações e serviços, para a prevenção, promoção, proteção e recuperação da saúde, incluindo a atenção especial às doenças que afetam preferencialmente os idosos.

Para os fins do presente estudo, destaca-se o parágrafo $3^{\circ}$, que indica expressamente que "é vedada a discriminação do idoso nos planos de saúde pela cobrança de valores diferenciados em razão da idade."

Referida disposição atende aos anseios da própria Lei dos Planos de Saúde $^{5}$, que externa a provisão nos seus artigos 15 e 35-E no seguinte sentido:

A variação das contraprestações pecuniárias estabelecidas nos contratos de produtos de que tratam o inciso I e o $\S 1^{\circ}$ do art. $1^{\circ}$ desta Lei, em razão da idade do consumidor, somente poderá ocorrer caso estejam previstas no contrato inicial as faixas etárias e os percentuais de reajustes incidentes em cada uma delas, conforme normas expedidas pela A.N.S., ressalvado o disposto no art. 35-E.

A partir de 5 de junho de 1998, fica estabelecido para os contratos celebrados anteriormente à data de vigência desta Lei que: I - qualquer variação na contraprestação pecuniária para consumidores com mais de sessenta anos de idade estará sujeita à autorização prévia da A.N.S.

Neste viés, tem-se que é ilegal a cobrança de valores diferenciados por faixa etária de usuários a partir de 60 (sessenta) anos de idade, evitando-se assim a discriminação dos idosos relativamente aos demais usuários dos planos de saúde. A majoração apenas e tão somente poderá ocorrer de forma anual e desde que autorizada pela A.N.S., que por força da Lei n. ${ }^{\circ}$ $9.961 / 2000^{11}$ detém a responsabilidade de controlar os aumentos de mensalidade dos planos de saúde.

Neste aspecto, atualmente está em vigência a Resolução Normativa n. ${ }^{\circ} 63$ de 22 de dezembro de 2003 da A.N.S. ${ }^{6}$, que evidencia a limitação a ser observada para adoção da variação de preço por faixa etária nos planos privados de assistência à saúde, com contratos celebrados a partir de $1^{\circ}$ de janeiro de 2004 . Esta resolução adota dez faixas etárias: 0 (zero) a 18 (dezoito) anos; 19 (dezenove) a 23 (vinte e três) anos; 24 (vinte e quatro) a 28 (vinte e oito) anos; 29 (vinte e nove) a 33 (trinta e três) anos; 34 (trinta e quatro) a 38 (trinta e oito) anos; 39 (trinta e nove) a 43 (quarenta e três) anos; 44 (quarenta e quatro) a 48 (quarenta e oito) anos; 49 (quarenta e nove) a 53 (cinquenta e três) anos; 54 (cinquenta e quatro) a 58 (cinquenta e oito) anos; 59 (cinquenta e nove) anos ou mais.

A Resolução deixa claro que os percentuais de variação em cada mudança de faixa etária deverão ser fixados pela operadora, sendo sempre observadas algumas condições: o valor fixado para a última faixa etária não poderá ser superior a seis vezes o valor da primeira faixa etária; a variação acumulada entre a sétima e a décima faixas não poderá ser superior à variação acumulada entre a primeira e a sétima faixas; as variações por mudança de faixa etária não podem apresentar percentuais negativos. Tais requisitos são de observância obrigatória e, caso descumpridos, é certo que resplandecem conduta ilegal das operadoras de plano de saúde, sendo passíveis de punição e discussão judicial.

Esta resolução expõe a variação de preço por faixa etária para contratos firmados a partir de $1^{\circ}$ de janeiro de 2004. Para avenças celebradas antes desta data, em especial antes de 2 de janeiro de 1999, os chamados "contratos antigos", tem-se por certo que não foram adaptados à nova legislação, de sorte que a majoração seguirá o que estiver previsto no contrato. A própria A.N.S. indica que, caso o instrumento não evidencie de forma clarividente a respeito do reajuste, este será limitado ao mesmo percentual de variação divulgado pela Agência para os planos celebrados após esta data ${ }^{14}$.

Saliente-se, por relevante, que neste específico caso não é necessária a prévia autorização da A.N.S. para utilização do índice atual para os contratos antigos, excetuando-se os casos em que as operadoras tiverem firmado Termo de Compromisso, estabelecendo a forma de apuração do reajuste a ser aplicado aos contratos firmados antes de $1^{\circ}$ de janeiro de 1999 e não adaptados à Legislação ${ }^{14}$. A A.N.S. disponibiliza no seu endereço 
eletrônico (http://www. ans. gov. br/planos-desaude-e-operadoras / espaco-do-consumidor/ reajustes - de-precos - de-planos-de-saude)

percentuais autorizados neste caso.

Não obstante a existência das referidas normas, o reajuste praticado pelas operadoras de planos de saúde é constantemente objeto de discussão judicial, visando a apuração de eventuais irregularidades por parte das operadoras. Por outro lado, não se desconhece a atuação dos órgãos de defesa do consumidor, orientando e explanando a respeito das possibilidades de reajustes de planos de saúde ${ }^{15}$. O Instituto de Defesa do Consumidor divulgou que os "planos de saúde e serviços financeiros continuam no topo do ranking de atendimentos no Idec", afirmando ainda que o assunto segue como campeão de insatisfação entre os consumidores ${ }^{16}$. Entrementes, da análise das disposições legais específicas, denota-se que aumentos abusivos das mensalidades dos planos de saúde a maiores de 60 (sessenta) anos não podem prevalecer, mesmo quando consideramos contratos coletivos.

O Poder Judiciário tem se mostrado contrário ao aumento abusivo das mensalidades de planos de saúde para idosos, decidindo em alguns casos levados à sua apreciação que os reajustes devem obedecer estritamente os índices praticados pela A.N.S.. No Recurso Especial 809329 - RJ ${ }^{17}$, a Rel. Ministra Nancy Andrighi, da Terceira Turma entendeu que:

apenas como reforço argumentativo, porquanto não prequestionada a matéria jurídica, ressalte-se que o art. 15 da Lei n. ${ }^{\circ}$ 9.656/98 faculta a variação das contraprestações pecuniárias estabelecidas nos contratos de planos de saúde em razão da idade do consumidor, desde que estejam previstas no contrato inicial as faixas etárias e os percentuais de reajuste incidentes em cada uma delas, conforme normas expedidas pela A.N.S.. No entanto, o próprio parágrafo único do aludido dispositivo legal veda tal variação para consumidores com idade superior a 60 anos. - E mesmo para os contratos celebrados anteriormente à vigência da Lei n. ${ }^{\circ}$ 9.656/98, qualquer variação na contraprestação pecuniária para consumidores com mais de 60 anos de idade está sujeita à autorização prévia da A.N.S. (art. 35-E, I, da Lei n. ${ }^{\circ}$ 9.656/98).

Essa constatação implica no reconhecimento que os idosos consumidores de plano de saúde, coletivos ou não, podem questionar judicialmente a aplicabilidade e a validade dos percentuais impostos pelas suas operadoras de plano de saúde, requerendo que o aumento seja realizado dentro dos limites autorizados pela A.N.S., cabendo também o pleito de declaração de nulidade da cláusula de reajuste com valores abusivos dos últimos dez anos de vigência do contrato e a devolução dos valores pagos a mais. Isso porque, muito embora a lição do art. 27 do C.D.C. ${ }^{4}$ indique o prazo prescricional de cinco anos para as relações de consumo, o Superior Tribunal de Justiça ${ }^{18,19}$ pacificou o entendimento de que a pretensão de reconhecimento de abusividade em cláusula contratual presente nos contratos de planos de saúde tem o prazo prescricional decenal.

Da mesma forma, quando se trata da previsão infraconstitucional a respeito da possibilidade do Ministério Público atuar como requerente de ação civil pública visando tutelar abusividade contratual e a responsabilidade por danos causados ao consumidor, nos termos da Lei n. ${ }^{0} 7.347 / 1985^{20}$, uma vez considerada a omissão na indicação de prazo em tal legislação, aplicar-se-á a subsidiariedade do Código Civil às relações de consumo, especificamente considerando a previsão do artigo 205 do Código Civil ${ }^{21}$ ratificada pelo posicionamento do $\mathrm{STJ}^{18}$, evidenciando-se então um prazo de dez anos contados da majoração da mensalidade ou da rescisão do contrato firmado entre o consumidor e a operadora de plano de saúde.

O presente tema, inclusive, é objeto de Súmulas do Tribunal de Justiça do Estado de São Paulo (TJ-SP) ${ }^{10,22}$, unificando o entendimento e pacificando a questão. Trata-se das Súmulas 91 e 100, assim delineadas: "Ainda que a avença tenha sido firmada antes da sua vigência, é descabido, nos termos do disposto no art. $15, \S 3^{\circ}$, do Estatuto do Idoso, o reajuste da mensalidade de plano de saúde por mudança de faixa etária"22. Reconhecendo a aplicabilidade do código consumerista, tem-se o teor da Súmula 100 do Tribunal de Justiça do Estado de São Paulo que indica que "O contrato de plano/seguro saúde submete-se aos ditames do C.D.C. e da Lei $n^{\circ}$ 9.656/98 ainda que a avença tenha sido celebrada antes da vigência desses diplomas legais" ${ }^{10}$.

A Resolução Normativa 63/2003 da A.N.S. ${ }^{6}$ é omissa a respeito de reajustes em razão da ocorrência da sinistralidade, que nada mais é do que um indicador financeiro que reflete a relação entre os custos sobre as receitas de uma operadora de plano de saúde. Entrementes, prevê que o valor fixado para a última faixa etária (59 anos ou mais) não poderá ser superior a seis vezes o valor da primeira faixa etária ( 0 a 18 anos), o que implica no reconhecimento da permissividade de majoração, respeitada essa faixa máxima de aumento.

No entanto, é importante salientar também que os idosos estão imunes de quaisquer aumentos abusivos no valor do plano de saúde ou rescisão unilateral em razão da alta sinistralidade. Visando disponibilizar informações que permitam o consumidor a escolha adequada do plano de saúde, a A.N.S. disponibiliza um painel de análise integrada dos dados de qualidade de saúde suplementar, reunindo informações sobre beneficiários, prestadores de serviços de saúde, operadoras de planos de saúde, aí incluída a menção as percentagens de sinistralidade de planos coletivos empresariais, coletivo por adesão, individual e outras informações correlatas ${ }^{23}$. 
Observando a reiterada ocorrência de utilização do plano de saúde, em especial para segurados idosos, as operadoras de planos de saúde poderiam negar-se a renovar as apólices ou até mesmo majorar ilicitamente o valor do plano. Por outro lado, há também a possibilidade de facultarem a adesão dos segurados à nova apólice, mas com evidente aumento no valor mensal.

No entanto, o Superior Tribunal de Justiça (STJ) já se manifestou contrariamente ao aumento da mensalidade do plano de saúde sob o argumento das operadoras de "alta sinistralidade". No julgamento do Recurso Especial n. 1.106.557 - SP (2008/0262553-6) ${ }^{24}$, a Relatora Ministra Nancy Andrighi, afirmou que:

a inserção e continuidade dos usuários do plano de saúde na condição de juridicamente idosos, do que decorre o alto índice de sinistralidade, é utilizada pela recorrida como único fato motivador da rescisão do contrato ou majoração do valor da mensalidade. Quando do julgamento do REsp 809.329/RJ, DJ de $11 / 4 / 2008$, que envolveu semelhante questão, explicitei, em meu voto, que o art. 15 da Lei n. ${ }^{\circ} 9.656 / 98$ faculta a variação das contraprestações pecuniárias estabelecidas nos contratos de planos de saúde em razão da idade do consumidor, desde que estejam previstas no contrato inicial as faixas etárias e os percentuais de reajuste incidentes em cada uma delas, conforme normas expedidas pela A.N.S.. No entanto, o próprio parágrafo único do aludido dispositivo legal veda tal variação para consumidores com idade superior a 60 anos.

Como corolário lógico, é certo que o consumidor que atingiu a idade de 60 anos, quer seja antes da vigência do Estatuto do Idoso, quer seja a partir de sua vigência ( $1^{\circ}$ de janeiro de 2004$)$, estará de fato amparado contra qualquer abusividade no que diz respeito aos reajustes nas mensalidades dos planos de saúde, com base exclusivamente na alta sinistralidade da apólice, em específico quando decorrente da faixa etária dos segurados. Certamente não se trata dos reajustes permitidos em lei, os quais obviamente são garantidos às empresas prestadoras de plano de saúde, sempre ressalvada a abusividade da pretensão ilegítima de discriminação do idoso em razão da idade.

Em recente julgamento do Supremo Tribunal Federal (STF), por outro lado, foi pacificado que, posteriormente a um "período de instabilidade jurisprudencial, com manifestação não uniforme sobre o tema, ambas as turmas de direito privado do STJ passaram a encampar entendimento único, no sentido de que o aumento da mensalidade de plano privado de saúde em virtude da alteração de faixa etária é lícito, uma vez que com o avançar da idade o segurado utiliza mais o serviço contratado. Esse incremento do preço, no entanto, para ser válido, deve ser proporcional e razoável, vindo os instrumentos contratuais com previsão expressa das faixas de idade (seja a avença anterior ou não à Lei ${ }^{\circ}$ 9.656/1998), em respeito ao art. $6^{\circ}$, III e art. 39, XI, do C.D.C. e como expressão dos deveres anexos"25.

A Ministra Relatora Rosa Weber sustentou no julgamento, ocorrido em $1^{\circ}$ de março de $2016^{25}$, que deve ser firmado "o entendimento de ser, a princípio, idôneo o reajuste de mensalidade de plano de saúde em razão da mudança de faixa etária do participante, pois com o incremento da idade há o aumento de risco de a pessoa vir a necessitar de serviços de assistência médica. Todavia, para evitar abusividades, devem ser observados alguns parâmetros, como a expressa previsão contratual; não serem aplicados índices de reajuste desarrazoados ou aleatórios, que onerem excessivamente o consumidor, em manifesto confronto com a equidade e a cláusula geral da boa-fé objetiva e da especial proteção do idoso, dado que aumentos elevados, sobretudo para essa última categoria, poderão, de forma discriminatória, impossibilitar a sua permanência no plano, e serem respeitadas as normas expedidas pelos órgãos governamentais (Resolução CONSU no 6/98 ou Resolução Normativa nº 63/2003 da A.N.S.). Logo, a abusividade dos aumentos das mensalidades de plano de saúde, sobretudo de participantes idosos, deverá ser aferida em cada caso concreto."

É certo que os contratos de seguro de assistência à saúde submetem-se ao C.D.C. ${ }^{4}$, sendo imprescindível o respeito aos deveres de informação e transparência. Por outro lado, é certo que a Lei no $9.656 / 1998^{5}$ e a Resolução $63 / 2003^{6}$ da A.N.S. também permitem o reajuste das parcelas decorrentes da mudança de faixa etária dos segurados, desde que exista previsão expressa indicando as faixas etárias, bem como os respectivos índices e percentuais de reajuste, com vistas a evitar-se o desequilíbrio contratual entre as partes contratantes e ofensas à relação de consumo desenvolvida.

Esta possibilidade de reajuste necessariamente tem que ser interpretada, contudo, à luz do Estatuto do Idoso, que veda expressamente o reajuste abusivo e desarrazoado, que representa verdadeiro fator de discriminação do idoso, justamente por visar dificultar ou impedir sua permanência no plano. Um parâmetro máximo parece advir do artigo $3^{\circ}$ da Resolução 63/2003 da A.N.S. ${ }^{6}$, que indica, como já exposto, que o valor fixado para a última faixa etária não poderá ser superior a seis vezes o valor da primeira faixa etária. No entanto, mesmo neste aspecto e considerando a ocorrência da sinistralidade, o reajuste deverá observar os critérios mencionados acima e definidos pelo STF.

Assim, tem-se que a abusividade deve ser repelida, entendendo também desta mesma forma o Tribunal de Justiça do Estado de São Paulo ${ }^{26-28}$, ratificando posicionamento do STF, afastando ilegalidades e abusividades no reajuste das mensalidades de plano de saúde em razão da idade do beneficiário. Nestes 
julgamentos, deferiu-se inclusive tutela antecipada para suspender os reajustes do plano de saúde, muito acima daquele anualmente autorizado pela Resolução Normativa da A.N.S. ${ }^{6}$ e infringindo o Estatuto do idoso ${ }^{28}$; observouse a presença de cláusulas abusivas, acarretando na devolução dos valores pagos a maior, provido, diante da inaplicabilidade da prescrição quinquenal à espécie ${ }^{27}$; e quando da presença de reajuste que visa burlar o Estatuto do Idoso, restituir os valores pagos a maior, com correção monetária e juros de mora ${ }^{26}$.

Frente ao exposto, observa-se que o singelo argumento das operadoras de plano de saúde no sentido de que a majoração do valor da mensalidade se daria em razão do aumento de sinistralidade do grupo é também uma forma de se discriminar o idoso, o que é vedado por expressa determinação legal. O ajuste da mensalidade nos planos de saúde de idosos deve ser analisado caso a caso, ser previsto expressa e claramente no contrato e respeitar os limites impostos pela Lei n. ${ }^{\circ}$ 9.656/985, Estatuto do Idoso ${ }^{3}$ e Código de Defesa do Consumidor ${ }^{4}$. A operadora deverá, com base nos princípios da informação e transparência advindos da análise conjunta dos artigos $4^{\circ}, 6^{\circ}$, inciso III, 47,51 e $54, \S 3^{\circ}$ do C.D.C. ${ }^{4}$, demonstrar pormenorizadamente a proporcionalidade entre a nova mensalidade e o potencial aumento de utilização de serviços, ou seja, provar a ocorrência de eventual desequilíbrio contratual de maneira a justificar o reajuste.

É certo que a oneração do consumidor idoso em montante superior ao que seria devido implica em privação material incompatível com a sistemática jurídica vigente, conforme exposto acima, mormente se tratando de sujeitos de direitos que se encontram em dois nichos de hipossuficiência especialmente previstos pela Constituição Federal², já que são consumidores (art. $5^{\circ}$, inciso XXXII; 170, inciso V) e idosos (art. 230 do mesmo diploma legal).

\section{CONSIDERAÇÕES FINAIS}

A aplicação das premissas oriundas da Constituição Federal no que diz respeito à proteção dos indivíduos idosos é corroborada pela legislação infraconstitucional, destacando-se o Estatuto do Idoso, o C.D.C. e a Lei dos Planos de Saúde, que atribuiu à A.N.S. o encargo de regulamentar tais questões.

Por mais que se observem a existência de previsão legislativa na proteção dos idosos e a inexistência de parâmetro fixo e definido claramente para reajuste de planos de saúde individuais ou coletivos dos idosos, a ocorrência das práticas ilegais e abusivas das operadoras de plano de saúde, em claro confronto com os direitos fundamentais das pessoas idosas é presente, o que justifica a necessidade da edição de normas específicas a fim de auxiliar os consumidores e definir os parâmetros legais no reajuste da mensalidade dos planos de saúde.

O reajuste do plano de saúde de idosos que não seja pormenorizadamente justificado, que não respeite as premissas da A.N.S., não tenha previsão contratual e não seja pautado na clara demonstração de suas justificativas, sendo proporcional e razoável, será considerado abusivo. Um parâmetro adequado para o limite de reajuste por mudança de faixa etária ou sinistralidade, deverá ser o previsto no artigo $3^{\circ}$ na Resolução da 63/2003 da A.N.S. Não possuindo tais caracteres, na esteira do recente posicionamento do Supremo Tribunal Federal, será considerado como ato de discriminação dos idosos, prática esta repelida pela Constituição Federal e pelo Estatuto do Idoso e considerado nulo de pleno direito, cabendo ainda ao consumidor idoso o pleito de ressarcimento dos valores indevidamente cobrados.

Tafelli D, Trujillo E, Aznar FDC, Freitas AR, Peres SHCS, Bastos JRM, Sales-Peres A, Caldana ML. Elderly people's rights pertaining to health insurance readjustment. Saúde, Ética \& Justiça. 2015;20(2):93-101.

\begin{abstract}
As the world's population grows older, authorities' attention has been drawn to the matter, creating the need to reassess current legislation, in order to create an environment for the elderly that provides more adequate and fair life conditions. Heedful of such reality, the Brazilian Federal Constitution addressed the concern of elderly health, therefore accounting for the legal protection of such individuals. However, the evolution of the right to health has proven to be slow and gradual, whereas only recently has the "Statute of the Elderly" been promulgated, which addresses the actual guarantee of non-adjustment of the prices of elderly healthcare plans beyond legally accepted thresholds, both regarding growth in age and usage. This article also discusses the applicability of the Code for Consumer Defense, which is a protective law applicable to contractual relationships, and that possesses its specific legal set of rule and dialogues with other legislations protective of the elderly. Therefore, this analysis intends to promote a critical and analytical view on the legislations and dominant jurisprudence regarding the impossibility of price raising of elderly healthcare beyond legal admittance. Hence, this article consists of the study of the evolution of related legislation, along with research from the websites of Brazilian Courts of Justice in order to collect data about recent legal decisions related to the matter. Several instances of abuse by healthcare operators have been observed, that increase their prices above legal limit in spite of legal prohibition.
\end{abstract}

KEY WORDS: Health of the elderly; Aged rights; Consumer advocacy; Prepaid health plans. 


\section{REFERÊNCIAS}

1. Damiance PRM, Arakawa AM, Franco EC, Coelho TRF, Santos MA, Lauris JRP, Caldana ML, Bastos JRM. Situação de saúde do idoso: ensino-pesquisa-extensão em um Município do Centro-Oeste Paulista. Rev Cultura Extensão USP. 2015;12(supl.):19-35. DOI: http://dx.doi. org/10.11606/issn.2316-9060.v12isupl.p19-35.

2. Brasil. Presidência da República, Casa Civil, Subchefia para assuntos jurídicos. Constituição da República Federativa do Brasil de 1988. Brasília, DF; 1988. Disponível em: http:/www.planalto.gov.br/ccivil_03/ Constituicao/Constituicao.htm.

3. Brasil. Presidência da República, Casa Civil, Subchefia para assuntos jurídicos. Lei $\mathrm{n}^{\circ} 10.741$, de $1^{\circ}$ de outubro de 2003. Dispõe sobre o Estatuto do Idoso e dá outras providências. Brasília, DF; 2003. Disponível em: http:// www.planalto.gov.br/ccivil_03/leis/2003/L10.741.htm.

4. Brasil. Presidência da República, Casa Civil, Subchefia para assuntos jurídicos. Lei $\mathrm{n}^{\circ} 8.078$, de 11 de setembro de 1990. Dispõe sobre a proteção do consumidor e dá outras providências. Brasília, DF; 1990. Disponível em: http:// www.planalto.gov.br/ccivil 03/leis/L8078.htm.

5. Brasil. Presidência da República, Casa Civil, Subchefia para assuntos jurídicos. Lei nº 9.656, de 3 de junho de 1998. Dispõe sobre os planos e seguros privados de assistência à saúde. Brasília, DF; 1988. Disponível em: http://www. planalto.gov.br/ccivil_03/leis/L9656.htm.

6. Agência Nacional de Saúde Suplementar (ANS). Resolução Normativa - RN n ${ }^{\circ} 63$, de 22 de dezembro de 2003. Define os limites a serem observados para adoção de variação de preço por faixa etária nos planos privados de assistência à saúde contratados a partir de $1^{\circ}$ de janeiro de 2004. Rio de Janeiro, RJ; 2003. Disponível em: http:// www.ans.gov.br/component/legislacao/?view=legislacao $\&$ task=TextoLei\&format $=$ raw\&id $=\mathrm{NzQ} 4$.

7. Paim J, Travassos C, Almeida C, Bahia L, Macinko J. O Sistema de saúde brasileiro: história, avanços e desafios. Lancet. 2011;377(9779):1778-97. DOI: http://dx.doi. org/10.1016/S0140-6736(11)60054-8.

8. Brasil. Superior Tribunal de Justiça. Agravo regimental no agravo de instrumento: 1250819 PR 2009/0222990-5. Agravo regimental em agravo de instrumento - seguro de saúde - contrato firmado antes da vigência da lei n. 9656/98 - obrigação de trato sucessivo - possibilidade de se aferir, nas renovações, a abusividade de cláusulas contratuais à luz do que dispõe a legislação consumerista - entendimento em harmonia com a jurisprudência deste tribunal - material essencial ao tratamento cirúrgico coberto pelo plano de saúde - cobertura - precedentes - recurso improvido. Diário da Justiça Eletrônico. 201018 mai. Disponível em: http://stj.jusbrasil.com.br/jurisprudencia/14353454/ agravo-regimental-no-agravo-de-instrumento-agrg-no-ag1250819-pr-2009-0222990-5/inteiro-teor-14353455.

9. Brasil. Superior Tribunal de Justiça. Súmula 469. Ementa: Aplica-se o Código de Defesa do Consumidor aos contratos de plano de saúde. Diário da Justiça Eletrônico, $06 \mathrm{dez}$ 2010. Disponível em: http://www.stj.jus.br/SCON/ sumanot/.

10. São Paulo. Tribunal de Justiça do Estado de São Paulo. Súmula 100: O contrato de plano/seguro saúde submetese aos ditames do Código de Defesa do Consumidor e da Lei n. 9.656/98 ainda que a avença tenha sido celebrada antes da vigência desses diplomas legais. Diário da Justiça Eletrônico. 28 fev 2013. Disponível em: https://www.dje. tjsp.jus.br/cdje/consultaSimples.do?cdVolume=7\&nuDiari $\mathrm{o}=1364 \&$ cdCaderno $=10$ \&nuSeqpagina $=1$.

11. Brasil. Presidência da República, Casa Civil, Subchefia para assuntos jurídicos. Lei $\mathrm{n}^{\circ} 9.961$, de 28 de janeiro de 2000. Cria a Agência Nacional de Saúde Suplementar - ANS e dá outras providências. Brasília, DF; 2000. Disponível em: http://www.planalto.gov.br/ccivil_03/leis/ L9961.htm.

12. Brito F. A transição demográfica no Brasil: as possibilidades e os desafios para a economia e a sociedade. Belo Horizonte: UFMG/Cedeplar; 2007. Disponível em: http:// www.cedeplar.ufmg.br/pesquisas/td/TD\%20318.pdf.

13. IBGE - Instituto Brasileiro de Geografia e Estatística. Pesquisa Nacional por amostra de domicílios. Um panorama da saúde no Brasil: acesso e utilização dos serviços, condições de saúde e fatores de risco e proteção à saúde - 2008. Rio de Janeiro, RJ; 2010. Disponível em: http://biblioteca.ibge.gov.br/visualizacao/monografias/ GEBIS\%20-\%20RJ/panorama.pdf.

14. ANS - Agência Nacional de Saúde Suplementar. Reajuste de preços de planos de saúde antigos. Rio de Janeiro, RJ. Disponível em: http://www.ans.gov.br/planos-de-saudee-operadoras/espaco-do-consumidor/512-reajustes-deprecos-de-planos-de-saude-antigos.

15. IDEC - Instituto Brasileiro de Defesa do Consumidor. Conheça os tipos de reajustes dos planos de saúde existentes. São Paulo, SP. Disponível em: http://www. idec.org.br/consultas/dicas-e-direitos/conheca-os-tipos-dereajuste-possiveis.

16. IDEC - Instituto Brasileiro de Defesa do Consumidor Nem o Básico. Rev IDEC. 2015;196:18-20.

17. Brasil. Superior Tribunal de Justiça. Recurso Especial 809329 RJ 2006/0003783-6. Direito civil e processual civil. Recurso especial. Ação revisional de contrato de plano de saúde. Reajuste em decorrência de mudança de faixa etária. Estatuto do idoso. Vedada a discriminação em razão da idade. Recurso especial não conhecido. Diário da Justiça, 4 abr 2008. Disponível em: http://stj.jusbrasil.com. br/jurisprudencia/604630/recurso-especial-resp-809329rj-2006-0003783-6

18. Brasil. Superior Tribunal de Justiça. Recurso especial 995995 DF 2007/0241447-0. Processual civil. Recurso especial. Ação civil pública. Ministério Público. Plano de saúde. Interesse individual indisponível. Reajuste. Cláusula abusiva. Prescrição. Art. 27 do cdc. Inaplicabilidade. 
Lei 7.347/85 omissa. Aplicação do art. 205 docc/02. Prazo prescricional de 10 anos. Recurso não provido. Diário da Justiça Eletrônico, 16 nov 2010. Disponível em: http://stj.jusbrasil.com.br/jurisprudencia/19133788/ recurso-especial-resp-995995-df-2007-0241447-0/inteiroteor-19133789.

19. Brasil. Superior Tribunal de Justiça. Recurso Especial 1241056 RS 2011/0045138-6. Plano de saúde. Ação revisional e repetição do indébito. Prazo prescricional decenal. Aplicação do art. 205 do código civil. Recurso provido. Diário da Justiça. 17 jun 2015. Disponível em: http://stj.jusbrasil.com.br/jurisprudencia/200054702/ recurso-especial-resp-1241056-rs-2011-0045138-6.

20. Brasil. Presidência da República, Casa Civil, Subchefia para assuntos jurídicos. Lei $n^{\circ} 7.347$, de 24 de julho de 1985. Disciplina a ação civil pública de responsabilidade por danos causados ao meio ambiente, ao consumidor, a bens e direitos de valor artístico, estético, histórico, turístico e paisagístico (vetado) e dá outras providências. Brasília, DF; 1985. Disponível em: http://www.planalto. gov.br/ccivil_03/leis/L7347orig.htm.

21. Brasil. Presidência da República, Casa Civil, Subchefia para assuntos jurídicos. Lei $\mathrm{n}^{\circ} 10.406$, de 10 de janeiro de 2002. Institui o Código Civil. Brasília, DF; 2002. Disponível em: http:/www.planalto.gov.br/ccivil 03/ leis/2002/110406.htm.

22. São Paulo. Tribunal de Justiça do Estado de São Paulo. Súmula 91: Ainda que a avença tenha sido firmada antes da sua vigência, é descabido, nos termos do disposto no art. $15, \S 3^{\circ}$, do Estatuto do Idoso, o reajuste da mensalidade de plano de saúde por mudança de faixa etária [Internet]. Diário da Justiça Eletrônico. 13 fev 2012. Disponível em: https://www.dje.tjsp.jus.br/cdje/consultaSimples.do?cdV olume $=7 \&$ nuDiario $=1364 \&$ cdCaderno $=10 \&$ nuSeqpagi na $=1$.

23. ANS - Agência Nacional de Saúde Suplementar. Dados Integrados de Qualidade Setorial. Rio de Janeiro, RJ. Disponível em: http://www.ans.gov.br/planos-de-saudee-operadoras/informacoes-e-avaliacoes-de-operadoras/ dados-integrados-da-qualidade-setorial

24. Brasil. Superior Tribunal de Justiça. Recurso Especial 1106557 SP 2008/0262553-6. Direito do consumidor. Estatuto do idoso. Planos de saúde. Rescisão de plano de saúde em razão da alta sinistralidade do contrato, caracterizada pela idade avançada dos segurados. Vedação. Diário da Justiça Eletrônico, 21 out 2010. Disponível em: http://stj.jusbrasil.com.br/jurisprudencia/17406501/ recurso-especial-resp-1106557-sp-2008-0262553-6

25. Brasil. Supremo Tribunal Federal. Agravo Regimental no Recurso Extraordinário 916.069 - MG. Decisão: A Turma negou provimento ao agravo regimental, nos termos do voto da Relatora. Unânime. Supremo Tribunal Federal. 1 mar 2016. Disponível em: http://www.stf.jus.br/portal/
processo/verProcessoAndamento.asp?incidente $=4849187$

26. São Paulo. Tribunal de Justiça do Estado de São Paulo. Agravo de Instrumento $\mathrm{n}^{\mathrm{o}}$ 2106327-13.2015.8.26.0000 SP. Agravo de instrumento - plano de saúde - Decisão que deferiu tutela antecipada para suspender os reajustes do plano de saúde do autor - Agravado que, aos 77 anos de idade sofreu reajuste no percentual de $28 \%$ em sua mensalidade do plano de saúde, muito acima daquele anualmente autorizado pela ANS - Aplicação do Estatuto do Idoso - Inteligência da Súmula $\mathrm{n}^{\circ} 91$ deste E. TJSP Recurso não provido. Tribunal de Justiça de São Paulo. 1 set 2015. Disponível em: http://tj-sp.jusbrasil.com.br/ jurisprudencia/227203512/agravo-de-instrumento-ai21063271320158260000-sp-2106327-1320158260000/ inteiro-teor-227203534

27. São Paulo. Tribunal de Justiça do Estado de São Paulo. Apelação Cível $n^{\circ}$ 0038892-48.2012.8.26.0554. Plano de saúde. Reajuste. Cláusula abusiva. Inaplicabilidade da prescrição ânua à espécie. Aplicação do prazo genérico prescricional, diante da ausência de norma específica no CDC. Prazo prescricional decenal. Aumento na mensalidade por mudança de faixa etária. Autora idosa. Inadmissibilidade. Ilegalidade e abusividade no reajuste da mensalidade, em razão da idade do beneficiário com mais de 60 anos. Aplicação do Estatuto do Idoso, do CDC e da Lei 9.656/98, sem ofensa ao ato jurídico perfeito. Inteligência da Súmula 91 do TJSP. Pleito de devolução dos valores pagos a mais, provido, diante da inaplicabilidade da prescrição quinquenal à espécie. Incidência da norma prevista no artigo 205 do Código Civil. Recurso adesivo da autora provido e negado provimento ao recurso da ré. Tribunal de Justiça de São Paulo. 2 set 2015. Disponível em: http://tj-sp.jusbrasil. com.br/jurisprudencia/227120310/apelacao-apl388924820128260554-sp-0038892-4820128260554/ inteiro-teor-227120348

28. São Paulo. Tribunal de Justiça do Estado de São Paulo. Apelação Cível no 1020085-93.2014.8.26.0100. Seguro saúde. Ação de obrigação de fazer. Preliminar de ilegitimidade ativa afastada Incidência da Súmula $\mathrm{n}^{\circ} 101$ do TJSP - Reajuste de $89,07 \%$ da mensalidade com base na faixa etária da autora, que atingiu 59 anos Inadmissibilidade Configurado desequilíbrio e abusividade contratual Inteligência do artigo 51, IV, do CDC. Reajuste que visa burlar o Estatuto do Idoso Reajuste por sinistralidade. Ausência de demonstração de descompasso entre os prêmios recebidos e os valores pagos pelos serviços usufruídos pelos beneficiários do plano. Reajuste por sinistralidade abusivo. Precedentes do TJSP. Recursos desprovidos. Tribunal de Justiça de São Paulo. 20 out 2014. Disponível em: http://tj-sp. jusbrasil.com.br/jurisprudencia/148809587/apelacao-ap110200859320148260100-sp-1020085-9320148260100/ inteiro-teor-148809598 